\title{
Proyecto
}

\section{Fundamentos de Historia - Historia Antigua y Medieval: Problemas y soluciones materiales}

Recepción: 06/04/2021 | Revisión: 07/08/2021 | Aceptación: 07/08/2021 | Publicación: 01/03/2022

iD Víctor SÁNCHEZ DOMÍNGUEZ

Universidad de Córdoba

vsanchez1@us.es

https://orcid.org/oooo-ooo3-1628-2914

iD Fernando LOZANO GóMEZ

Universidad de Sevilla

flozanogomez@us.es

https://orcid.org/oooo-0002-3850-5800

\author{
Alfonso ÁLVAREZ-OSSORIO RIVAS \\ Universidad de Sevilla \\ alfossorio@us.es \\ https://orcid.org/oooo-0002-9450-0369
}

Resumen: Fundamentos de Historia corresponde a una serie de proyectos de innovación docente financiados por el vicerrectorado de estudiantes de la Universidad de Sevilla, cuyo objetivo primero fue identificar las necesidades de los alumnos a la hora de cursar la asignatura homónima introducida en el plan de estudios del Grado de Educación Primaria en 2010. Las investigaciones sobre ideas previas y la experiencia de los grupos docentes plantearon la necesidad de dar respuesta a la problemática detectada a través de un segundo proyecto, cuyo objetivo fue el diseño de materiales específicos para el alumnado de esta asignatura, así como para alumnos de los primeros cursos de grados de Historia.

En esta aportación presentamos el diseño, desarrollo y resultados de los proyectos correspondientes al curso 2011-12 y al curso 2016-17, siendo el primero una investigación sobre el nivel inicial de los alumnos mediante el diseño y aplicación de cuestionarios de evaluación inicial y el segundo, un proyecto de elaboración de materiales que culminó con la publicación del manual Fundamentos de Historia, Historia Antigua y Medieval de España.

Palabras clave: historia antigua; didáctica de las Ciencias Sociales; educación superior; innovación docente; diseño de materiales.

\section{FUNDAMENTALS OF HISTORY - ANCIENT AND MEDIEVAL HISTORY: MATERIAL PROBLEMS AND SOLUTIONS}

Abstract: Fundamentals of History corresponds to a series of teaching innovation projects funded by the Vice-Rectorate for Students of the University of Seville, whose first objective was to identify the 
needs of students when taking the subject of the same name, introduced in the curriculum of the Primary Education Degree in 2010. Research into previous ideas and the experience of the teaching groups led to the need to respond to the problems detected through a second project, the aim of which was to design specific materials for the students of this subject, as well as for students in the first years of the History degree courses.

In this contribution we present the design, development and results of the projects corresponding to the 2011-12 and 2016-17 academic years. The first is an investigation into the initial level of students through the design and application of initial assessment questionnaires and the second is a project to develop materials that culminated in the publication of the manual Fundamentals of History, Ancient and Medieval History of Spain.

Keywords: ancient history; didactics of Social Sciences; higher education; teaching innovation; design of materials.

\section{FONAMENTS D'HISTÒRIA - HISTÒRIA ANTIGA I MEDIEVAL: PROBLEMES I SOLUCIONS MATERIALS}

Resum: Fonaments d'Història correspon a una sèrie de projectes d'innovació docent finançats pel vicerectorat d'estudiants de la Universitat de Sevilla, l'objectiu dels quals fou identificar les necessitats dels alumnes a l'hora de cursar l'assignatura amb el mateix nom introduïda en el pla d'estudis del Grau d'Educació Primària l'any 2010. Les investigacions sobre idees prèvies i l'experiència dels grups docents van plantejar la necessitat de donar resposta a la problemàtica detectada a través d'un segon projecte, l'objectiu del qual fou el disseny de materials específics per a l'alumnat d'aquesta assignatura, així com per a alumnes dels primers cursos de graus d'Història.

En aquesta aportació presentem el disseny, desenvolupament i resultats dels projectes corresponents al curs 2011-12 i al curs 2016-17, essent el primer una investigació sobre el nivell inicial dels alumnes mitjançant el disseny i aplicació de qüestionaris d'avaluació inicial, i el segon, un projecte d'elaboració de materials que va culminar amb la publicació del manual Fundamentos de Historia, Historia Antigua y Medieval de España.

Paraules clau: història antiga; didàctica de les Ciències Socials; educació superior; innovació docent; disseny de materials.

\section{Introducción}

Durante la última década profesores del Departamento de Historia Antigua de la Universidad de Sevilla han diseñado y llevado a cabo cinco proyectos de innovación docente financiados por el vicerrectorado de estudiantes, un esfuerzo colectivo para mejorar la enseñanza de la Historia en el aula universitaria. Los proyectos que presentamos aquí corresponden a:

- "Fundamentos de Historia. Historia de España" (2011). Cuyo objetivo principal era investigar sobre los conocimientos previos de Historia de los estudiantes del Grado en Educación.

- "Innovación y mejora docente en Historia Antigua: elaboración de nuevos materiales" (2016). Cuyo objetivo principal era el diseño y redacción de nuevo material de clase. 
El objetivo principal de los proyectos fue promover el aprendizaje y mejorar el desempeño y las posibilidades intelectuales de los estudiantes generando un tipo de aprendizaje autónomo, aunque dirigido, que maximizara el esfuerzo tanto del alumno como de los propios profesores (Benito y Cruz 2010; Prieto, 2008; Sánchez Domínguez et al., 2019). Se buscó promover el pensamiento crítico y ayudar a formar mejores profesionales presentándoles la Historia en toda su complejidad, sin simplificarla, despertando su interés por una disciplina en constante cambio y al mismo tiempo mejorando el conocimiento general de la misma.

\section{Fundamentación teórica}

Como bien recuerdan Gomez-Carrasco y Miralles-Martínez, "la historia es explicación, interpretación, en definitiva, pensamiento" (2015, p. 55) valiéndonos para formar el pensamiento crítico del alumnado; pero, a la vez, como afirman Prats y Santacana (2011), el alumnado debe aprender a leer las fuentes, para descubrir la información que el objeto lleva consigo. Así, formar en el pensamiento crítico a la vez que potenciar el uso de las fuentes para generar un aprendizaje autónomo han sido claves en estos proyectos.

Sin embargo, para conseguirlo era necesario profundizar en una evaluación de las ideas previas y plantearnos cuáles son los retos que plantea la didáctica de la materia, así como el nuevo alumnado. La enseñanza de la historia exige del conocimiento de la disciplina, su epistemología y sus fuentes (Carrasco et al., 2014) y nuestro alumnado, muy próximo aún a la educación secundaria, mantenía una serie de limitaciones y dificultades como son la existencia de prejuicios, la tendencia a la simplificación, la percepción de lejanía con respecto a la materia e incluso problemas de percepción derivadas del contenido abstracto que el alumno traslada a las técnicas de análisis propias de las Ciencias Sociales (Sánchez-Domínguez et al., 2019, p. 346-347).

\section{Metodología}

Para identificar las ideas previas realizamos un cuestionario con treinta preguntas tipo test con diferentes grados de complejidad. Para su elaboración usamos libros de texto de enseñanza secundaria y bachillerato, para trabajar con materiales conocidos por nuestros alumnos de segundo de grado. El cuestionario fue realizado por 364 estudiantes entre febrero y abril de 2012. Los resultados de este análisis y nuestra práctica docente nos empujaron a crear un nuevo tipo de manual que se ajustara a las necesidades de los estudiantes. Éste se desarrolló por medio del proyecto 2016-17 promoviendo una búsqueda bibliográfica y una elaboración de los materiales por el equipo docente (entre 2012 y 2017) quien seleccionó y coordinó a diferentes especialistas que completaron los contenidos.

En este libro, 12 profesores especialistas en Historia Antigua y Medieval adaptamos contenidos y materiales a las necesidades de los alumnos inspirándonos en revistas como National Geographic, Iberia Vieja, Desperta Ferro... las cuales estudiamos tanto en su composición, como en el tipo de información que incorporaban, el formato e incluso su difusión (Sánchez-Domínguez et al., 2019). Se diseñó un libro que se presentó en formato digital y de libre acceso (https://idus.us.es/handle/11441/55473) dividido en seis capítulos compuestos por: 
- Presentaciones: a doble página, donde se combinaron imágenes clave, con un breve resumen, cronograma y mapas con el objetivo de dar a los estudiantes la información básica.

- El texto de capítulo: con numerosas imágenes, fuentes y material explicativo, así como secciones destinadas a proporcionar a los estudiantes ideas para sus futuras clases en la escuela. Estas secciones están separadas del cuerpo de texto.

- Anexos didácticos, concretamente 12 ejemplos de unidades didácticas, inspiradas en la experiencia de implantación del sistema de evaluación práctica de la asignatura. El objetivo era que estos ejemplos sirvieran de modelo para sus propias clases.

- El libro también incluyó una bibliografía actualizada.

Para la evaluación del manual realizamos un análisis de los resultados centrándonos en la evolución académica de varios grupos de estudiantes, siguiendo criterios de continuidad del profesorado y necesidad de generar un grupo de control en el que el nuevo manual aún no hubiera sido incorporado.

\section{Resultados y conclusiones}

En relación al cuestionario de conocimientos previos los resultados mostraron los siguientes porcentajes (Figura 1):

Un $13 \%$ presentaron un nivel de conocimientos previos ínfimo, con un promedio de aciertos inferior a 10 preguntas de 30 , y un 39,53 \% insuficiente, ascendiendo la suma de ambos a $52,53 \%$.

Por otro lado, se observa un $44 \%$ de alumnos que tenían unas nociones básicas de la Historia de España, dato favorable para el desarrollo de la asignatura.

Sin embargo, destaca el escaso número de alumnos que alcanzó un nivel óptimo con solo un $3 \%$ que superaron los 20 aciertos.

En cuanto al impacto del manual desde 2015-16 (Tabla 1), momento en el que se comienzan a introducir las primeras versiones del manual, se percibió un descenso en relación a los alumnos que suspendían y un leve descenso en los no presentados (esta variación no se aprecia en el grupo de control). Se constató en ambos grupos una mejora constante en los resultados, debida a la familiarización con los grupos, contenidos y metodología, aunque el grupo que incorporó los nuevos materiales experimentó descenso en porcentaje evaluado con la nota de aprobado, esto se debió a la mejoría en calificaciones a notable y sobresaliente, un fenómeno que no se detectó de manera tan marcada en el grupo de control

Con estos datos podemos afirmar que la introducción del manual y el cambio de metodología docente han supuesto una mejora en los resultados académicos, en el nivel de participación del alumno en las clases, así como en el dinamismo con el que transcurren las mismas. Este progreso ha servido para continuar mejorando la accesibilidad y variedad de materiales, 
incorporando a través de nuevos proyectos de innovación docente mejoras metodológicas y nuevas herramientas docentes.

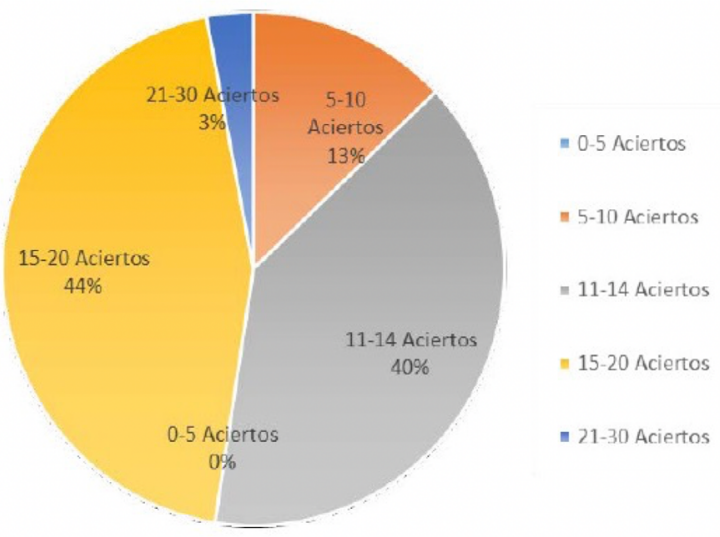

Figura 1. Gráfico cuestionario ideas previas. Elaboración: Propia.

\begin{tabular}{|l|l|l|l|l|l|l|}
\hline Notas & \multicolumn{2}{|l|}{$\begin{array}{l}\text { Alumnos (\%) } \\
2014 / 2015\end{array}$} & \multicolumn{2}{l|}{$\begin{array}{l}\text { Alumnos } 2015 / 2016 \\
\text { 201 }\end{array}$} & \multicolumn{2}{l|}{$\begin{array}{l}\text { Alumnos } \\
2016 / 2017\end{array}$} \\
\hline & Grupo & Control & Grupo & Control & Grupo & Control \\
\hline $\begin{array}{l}\text { No } \\
\text { presentados }\end{array}$ & 32,37 & 11,3 & 24,60 & 30 & 15,27 & 20,30 \\
\hline Suspenso & 23,02 & 18,90 & 15,18 & 18,33 & 20,13 & 23,40 \\
\hline Aprobado & 22 & 50,90 & 8,37 & 21,66 & 8,33 & 26,60 \\
\hline Notable & 15,82 & 13,2 & 39,78 & 23,33 & 35,41 & 28,10 \\
\hline Sobresaliente & 1,43 & 1,9 & 9,94 & 1,66 & 9,92 & 0 \\
\hline $\begin{array}{l}\text { Matrícula de } \\
\text { Honor }\end{array}$ & 4,31 & 3,8 & 2,09 & 5 & 4,16 & 1,6 \\
\hline
\end{tabular}

Tabla 1 Evolución de evaluaciones. Elaboración: Propia

\section{Referencias}

Benito, Á. y Cruz, A. (2012), Nuevas claves para la Docencia Universitaria en el Espacio Europeo de Educación Superior. Narcea.

Gómez Carrasco, C. J., Ortuño Molina, J. y Molina Puche, S. (2014) Aprender a pensar históricamente. Retos para la historia en el siglo XXI Revista Tempo e Argumento, 6(11), 5-27.

https://doi.org/10.5965/2175180306112014005

Gómez-Carrasco, C. J. y Mirallez-Martínez D, P. (2015) ¿Pensar históricamente o memorizar el pasado? La evaluación de los contenidos históricos en la educación obligatoria en España. Revista de Estudios Sociales, 52, 52-68. http://dx.doi.org/10.7440/res52.2015.04

Prieto Navarro, L. (2008) La enseñanza universitaria centrada en el aprendizaje. Estrategias para el profesorado. Octaedro.

Sánchez-Domínguez, V., Álvarez-Ossorio Rivas, A. y Lozano-Gómez, F. (2019). Nuevos alumnos, nuevos retos y recursos diferentes: un libro digital para la enseñanza de la Historia Antigua. El Futuro del Pasado: Revista Electrónica de Historia, 10, 343-372. 